\title{
Different Pain, Different Brain: Thalamic Anatomy in Neuropathic and Non-Neuropathic Chronic Pain Syndromes
}

\author{
Sylvia M. Gustin, ${ }^{1,2}$ Chris C. Peck, ${ }^{2}$ Sophie L. Wilcox, ${ }^{1}$ Paul G. Nash, ${ }^{1}$ Greg M. Murray, ${ }^{2}$ and Luke A. Henderson ${ }^{1}$ \\ ${ }^{1}$ Department of Anatomy and Histology, University of Sydney, Sydney, New South Wales, Australia, 2006, and ${ }^{2}$ Faculty of Dentistry, Jaw Function and \\ Orofacial Pain Research Unit, University of Sydney, Westmead Hospital, Westmead, New South Wales, Australia, 2145
}

\begin{abstract}
Trigeminal neuropathic pain (TNP) and temporomandibular disorders (TMD) are thought to have fundamentally different etiologies. It has been proposed that TNP arises through damage to, or pressure on, somatosensory afferents in the trigeminal nerve, whereas TMD results primarily from peripheral nociceptor activation. Because some reports suggest that neuropathic pain is associated with changes in brain anatomy, it is possible that TNP is maintained by changes in higher brain structures, whereas TMD is not. The aim of this investigation is to determine whether changes in regional brain anatomy and biochemistry occur in both conditions. Twenty-one TNP subjects, $20 \mathrm{TMD}$ subjects, and 36 healthy controls were recruited. Voxel-based morphometry of T1-weighted anatomical images revealed no significant regional gray matter volume change in TMD patients. In contrast, gray matter volume of TNP patients was reduced in the primary somatosensory cortex, anterior insula, putamen, nucleus accumbens, and the thalamus, whereas gray matter volume was increased in the posterior insula. The thalamic volume decrease was only seen in the TNP patients classified as having trigeminal neuropathy but not those with trigeminal neuralgia. Furthermore, in trigeminal neuropathy patients, magnetic resonance spectroscopy revealed a significant reduction in the $\mathrm{N}$-acetylaspartate/creatine ratio, a biochemical marker of neural viability, in the region of thalamic volume loss. The data suggest that the pathogenesis underlying neuropathic and non-neuropathic pain conditions are fundamentally different and that neuropathic pain conditions that result from peripheral injuries may be generated and/or maintained by structural changes in regions such as the thalamus.
\end{abstract}

\section{Introduction}

Chronic pain exists in a number of different forms, and the etiologies of many are not well understood. Although most chronic pain investigations have focused on peripheral targets such as nociceptors and their terminations, there is evidence that changes within higher brain centers may also be important for the maintenance and/or development of some chronic pain conditions. For example, many chronic pain conditions are associated with gray matter losses in a number of brain regions associated with acute pain processing, i.e., primary and secondary somatic areas, insula, thalamus, and cingulate cortex (Apkarian et al., 2004; Kuchinad et al., 2007; Schmidt-Wilcke et al., 2007; Buckalew et al., 2008; DaSilva et al., 2008; Kim et al., 2008; Schweinhardt et al., 2008; Burgmer et al., 2009; Gustin et al., 2010; Younger et al., 2010). Despite numerous investigations reporting brain anatomy changes associated with chronic pain, it remains unknown what

Received Nov. 14, 2010; revised Feb. 10, 2011; accepted Feb. 18, 2011.

Author contributions: S.M.G., C.C.P., G.M.M., and L.A.H. designed research; S.M.G., C.C.P., S.W., P.G.N., G.M.M., and L.A.H. performed research; S.M.G., S.W., P.G.N., and L.A.H. analyzed data; S.M.G., C.C.P., S.W., G.M.M., and L.A.H. wrote the paper.

The authors declare no competing financial interests.

This work was supported by National Health and Medical Research Council Grant 457342 and the Australian Dental Research Foundation Inc. We thank Kirsten Moffat for help in all imaging procedures. Scans were performed at the Prince of Wales Imaging Centre.

Correspondence should be addressed to Luke A. Henderson, Department of Anatomy and Histology, University of Sydney, School of Medical Sciences, Bosch Institute, F13 Anderson Stuart Building, Sydney, New South Wales, Australia, 2006. E-mail: lukeh@anatomy.usyd.edu.au.

DOI:10.1523/JNEUROSCI.5980-10.2011

Copyright $\odot 2011$ the authors $\quad 0270-6474 / 11 / 315956-09 \$ 15.00 / 0$ these gray matter changes represent and whether these changes are uniformly expressed in all chronic pain conditions regardless of their etiology.

In general, chronic pain results from either central or peripheral somatosensory system damage [neuropathic pain (Treede et al., 2008)] or from the constant nociceptor activation. Although many neuropathic pain conditions are initiated by peripheral nerve injury, neuropathic pain can occur after a centrally located stroke, i.e., central post-stroke pain (CPSP), which usually involves damage to the spinothalamic tract or thalamic ventroposterior nucleus (VP) (Kim, 1992; Kim et al., 2007). The development of CPSP highlights the fact that neuropathic pain can result from changes restricted to the brain, without the need for "peripheral" changes. Similar to CPSP, neuropathic pain after spinal cord injury is associated with thalamic anatomical changes, the extent of which is correlated with pain intensity (Apkarian et al., 2004; Gustin et al., 2010). Furthermore, VP thalamic stimulation can produce pain (Lenz et al., 1993; Davis et al., 1996) and increased thalamic bursting activity and biochemical changes indicative of neuronal loss occur in patients with pain after spinal cord injury (Lenz et al., 1989; Pattany et al., 2002). In direct contrast to neuropathic pain conditions, pain associated with temporomandibular disorders (TMD) results primarily from the activation of peripheral nociceptors (Sarlani and Greenspan, 2005; Ro, 2008; Sessle et al., 2008; Manfredini and Nardini, 2010 ) and, furthermore, is associated with thalamic gray matter volume increases (Younger et al., 2010). Given this, it is possible that the thalamus plays differential roles in the maintenance and/or generation of different forms of chronic pain. 
Table 1. Characteristics of TMD subjects

\begin{tabular}{|c|c|c|c|c|c|c|c|}
\hline Subject & $\begin{array}{l}\text { Age } \\
\text { (years) }\end{array}$ & Gender & $\begin{array}{l}\text { Duration of } \\
\text { pain (years) }\end{array}$ & Site & $\begin{array}{l}\text { Pain intensity week } \\
\text { before scanning } \\
\text { (10 cm VAS) }\end{array}$ & $\begin{array}{l}\text { Pain intensity before } \\
\text { scan ( } 10 \mathrm{~cm} \text { VAS) }\end{array}$ & Analgesic medication \\
\hline 151 & 38 & $\mathrm{~F}$ & 6 & Right & 1.8 & 4.7 & Paracetamol \\
\hline 201 & 59 & M & 20 & Bilateral & 5.9 & 6.0 & Amitriptyline hydrochloride \\
\hline 203 & 59 & $\mathrm{~F}$ & 30 & Bilateral & 7.9 & 7.6 & Venlafaxine, co-codamol \\
\hline 206 & 53 & $\mathrm{~F}$ & 3 & Bilateral & 2.5 & 3.1 & None \\
\hline 228 & 47 & M & 20 & Bilateral & 2.9 & 2.7 & Paracetamol (PRN) \\
\hline 253 & 42 & $\mathrm{~F}$ & 3 & Bilateral & 0.2 & 0 & None \\
\hline 256 & 70 & $\mathrm{~F}$ & 11 & Bilateral & 0.7 & 4.6 & Aspirin \\
\hline 259 & 62 & $\mathrm{~F}$ & 5 & Bilateral & 5.4 & 3.9 & Diazepam, paracetamol \\
\hline 267 & 45 & $\mathrm{~F}$ & 2 & Bilateral & 1.5 & 1.1 & None \\
\hline 268 & 37 & M & 6 & Bilateral & 7.3 & 7.0 & Botox \\
\hline 275 & 41 & $\mathrm{~F}$ & 4 & Right & 1.4 & 0.5 & None \\
\hline 290 & 50 & $\mathrm{~F}$ & 46 & Bilateral & 4.3 & 6.5 & Diclofenac \\
\hline 294 & 45 & $\mathrm{~F}$ & 5.5 & Bilateral & 4.1 & 7.3 & $\begin{array}{l}\text { Oxycodone (PRN), paracetamol, co-codamol (PRN), } \\
\text { doxylamine succinate, and codeine }\end{array}$ \\
\hline 295 & 33 & $\mathrm{~F}$ & 15 & Right & 5.9 & 5.5 & Doxylamine succinate and codeine (PRN) \\
\hline 300 & 28 & M & 1.5 & Bilateral & 5.8 & 6.7 & Ibuprofen (PRN) \\
\hline 301 & 24 & $\mathrm{~F}$ & 7 & Bilateral & 5.5 & 5.9 & Amitriptyline hydrochloride, co-codamol, and sumatriptan \\
\hline 304 & 66 & $\mathrm{~F}$ & 5 & Bilateral & 3.1 & 1.1 & None \\
\hline 313 & 50 & $\mathrm{~F}$ & 3 & Bilateral & 2.7 & 2.0 & None \\
\hline 314 & 37 & $\mathrm{~F}$ & 4 & Bilateral & 2.2 & 5.5 & lbuprofen (PRN) \\
\hline 317 & 30 & $\mathrm{~F}$ & 2 & Bilateral & 3.5 & 1.7 & Ibuprofen and paracetamol \\
\hline Mean \pm SEM & $46 \pm 2.9$ & & $11.5 \pm 3.4$ & & $3.7 \pm 0.5$ & $4.2 \pm 0.5$ & \\
\hline
\end{tabular}

All TMD patients fulfilled the criteria for TMD according to the Research Diagnostic (riteria for TMD (Dworkin and LeResche, 1992). PRN, Pro re nata ("as needed"); F, female; M, male.

Table 2. Trigeminal neuropathic pain subjects characteristics

\begin{tabular}{|c|c|c|c|c|c|c|c|c|}
\hline Subject & $\begin{array}{l}\text { Age } \\
\text { (years) }\end{array}$ & Gender & $\begin{array}{l}\text { Pain duration } \\
\text { (years) }\end{array}$ & Site & $\begin{array}{l}\text { TNP } \\
\text { subcategory }\end{array}$ & $\begin{array}{l}\text { Mean pain intensity } \\
\text { week before scanning } \\
\text { (10 cm VAS) }\end{array}$ & $\begin{array}{l}\text { Pain intensity before } \\
\text { scan ( } 10 \mathrm{~cm} \text { VAS) }\end{array}$ & Analgesic medication \\
\hline 174 & 73 & $\mathrm{~F}$ & 35 & Right & Neuralgia & 3.9 & 4 & None \\
\hline 178 & 51 & M & 3.5 & Right & Neuropathy & 2.1 & 5.5 & Amitriptyline hydrochloride \\
\hline 179 & 48 & $\mathrm{~F}$ & 9 & Bilateral & Neuropathy & 2.5 & 2.5 & Gabapentin \\
\hline 181 & 42 & $\mathrm{~F}$ & 2 & Right & Neuropathy & 5.5 & 1.3 & Neurontin \\
\hline 182 & 64 & $\mathrm{~F}$ & 11 & Right & Neuropathy & 5 & 5 & Gabapentin \\
\hline 194 & 52 & $\mathrm{~F}$ & 3.5 & Right & Neuropathy & 4.5 & 0 & None \\
\hline 229 & 47 & $\mathrm{~F}$ & 5 & Left & Neuropathy & 1.1 & 1.9 & None \\
\hline 252 & 67 & $\mathrm{~F}$ & 20 & Left & Neuralgia & 2.8 & 3.0 & Baclofen \\
\hline 257 & 50 & M & 6 & Left & Neuralgia & 2.3 & 0 & Pregabalin \\
\hline 260 & 60 & $\mathrm{~F}$ & 6 & Bilateral & Neuralgia & 3.2 & 2.4 & Celecoxib, paracetamol \\
\hline 261 & 53 & $\mathrm{~F}$ & 2.5 & Right & Neuropathy & 1.5 & 1.1 & None \\
\hline 262 & 52 & $\mathrm{~F}$ & 1.5 & Bilateral & Neuropathy & 6.9 & 6.1 & Gabapentin, oxycodone, and paracetamol \\
\hline 264 & 55 & $\mathrm{~F}$ & 2 & Left & Neuropathy & 5.2 & 6.7 & $\begin{array}{l}\text { Amitriptyline hydrochloride, gabapentin, oxycodone } \\
\text { hydrochloride, and paracetamol }\end{array}$ \\
\hline 265 & 75 & $\mathrm{~F}$ & 35 & Right & Neuralgia & 0.5 & 0.3 & Gabapentin and carbamazepine \\
\hline 266 & 46 & M & 9 & Bilateral & Neuropathy & 3.1 & 1.8 & None \\
\hline 269 & 62 & $\mathrm{~F}$ & 7 & Right & Neuralgia & 4.8 & 6.3 & None \\
\hline 276 & 46 & $\mathrm{~F}$ & 3 & Bilateral & Neuropathy & 6.5 & 5.2 & Diazepam, paracetamol, and ibuprofin (PRN) \\
\hline 280 & 42 & $\mathrm{~F}$ & 11 & Bilateral & Neuropathy & 4.8 & 4.0 & Carbamazepine and paracetamol \\
\hline 291 & 56 & M & 2 & Left & Neuralgia & 0.9 & 0.4 & Carbamazepine \\
\hline 340 & 48 & $\mathrm{~F}$ & 1.3 & Bilateral & Neuropathy & 2.6 & 3.2 & Gabapentin \\
\hline 341 & 61 & $\mathrm{~F}$ & 2.5 & Right & Neuralgia & 3.1 & 2.8 & None \\
\hline Mean \pm SEM & $55 \pm 2.1$ & & $8.5 \pm 2.1$ & & & $3.5 \pm 0.4$ & $3.4 \pm 0.5$ & \\
\hline
\end{tabular}

All trigeminal neuralgia patients and trigeminal neuropathy patients fulfilled the criteria for trigeminal neuropathic pain according to the Liverpool criteria (Nurmikko and Eldridge, 2001). PRN, Pro re nata ("as needed"); $\mathrm{F}$, female; $\mathrm{M}$, male.

The aim of this investigation is to use voxel-based morphometry (VBM) and magnetic resonance spectroscopy (MRS) to determine brain anatomy and biochemistry changes in two orofacial pain conditions: trigeminal neuropathic pain (TNP) and TMD. We hypothesize that TNP but not TMD is associated with reductions in thalamic volume and biochemistry and that these thalamic changes are correlated with ongoing pain intensity. Understanding differences in brain anatomy associated with different forms of chronic pain may ultimately lead to a better understanding of how to treat more effectively patients with various forms of chronic pain.

\section{Materials and Methods}

Subjects

Twenty-one subjects with TNP (four males, $19 \%$ males; mean \pm SEM age, $54.7 \pm 2.1$ years; range, $42-75$ years), 20 subjects with TMD (four males, $20 \%$ males; mean age, $45.7 \pm 2.9$ years; range, $28-70$ years), and 36 healthy 
controls without facial pain were recruited for the study at the Faculty of Dentistry, Westmead Hospital, University of Sydney (Sydney, Australia). Because the age and gender proportions of the TNP and TMD patient groups were different, two different age- and gender-matched control groups were used for the VBM analysis. For comparison with the TNP group, 30 control subjects were used (six males, $20 \%$ males; mean age, $53.6 \pm 3.2$ years; range, $24-87$ years), and for comparison with TMD patients, 31 control subjects were used (six males, $19 \%$ males; mean age, $46.8 \pm$ 3.3 years; range, $21-87$ years). All TNP patients were diagnosed according to the Liverpool criteria (Nurmikko and Eldridge, 2001). Thirteen of the TNP patients were classified as having trigeminal neuropathy $(n=13)$, i.e., dull or sharp continuous pain, often hours in duration with shooting pain superimposed. It has been suggested that trigeminal neuropathy likely results from direct trauma to the trigeminal nerve (Nurmikko and Eldridge, 2001). The remaining eight TNP patients were classified as having trigeminal neuralgia, i.e., sharp, shooting pain that lasts seconds to minutes. In contrast to trigeminal neuropathy, recent evidence suggests that trigeminal neuralgia results from compression of the trigeminal nerve root, at or near the dorsal root entry zone by a blood vessel, tumor, or multiple sclerosis plaque (Nurmikko and Eldridge, 2001; Sarlani et al., 2005). All TMD patients were diagnosed using the research diagnostic criteria for TMD (Dworkin and LeResche, 1992). Informed written consent was obtained for all procedures, and the study was approved by Institutional Human Research Ethics Committees of Westmead Hospital and the University of Sydney.

\section{MRI acquisition}

Subjects lay supine on the bed of a 3 T MRI scanner (Philips, Intera) with their head immobilized in a tight-fitting head coil. In each TNP, TMD, and control subject, three high-resolution three-dimensional (3D) T1weighted anatomical image sets, covering the entire brain were collected (turbo field echo; echo time, $2.5 \mathrm{~ms}$; repetition time, $5600 \mathrm{~ms}$; flip angle, $8^{\circ}$; voxel size, $0.8 \times 0.8 \times 0.8 \mathrm{~mm}$ ). Three acquisitions were acquired to improve signal-to-noise ratios. In the initial VBM analysis (described below), we found significant changes in gray matter volume within the thalamus. As a consequence, to determine whether the thalamic volume changes were in a thalamic somatosensory nucleus, the location of the ventroposterior nucleus was determined by assessing thalamic activation during innocuous brushing of the lip. That is, in addition to $\mathrm{T} 1$ anatomical scans, in all subjects, a series of 130 gradient echo echo-planar functional MRI (fMRI) image volumes using blood oxygen level-dependent contrast was collected. Each image volume contained 43 axial slices covering the entire brain (voxel, $1.95 \times 1.95 \times$ $3.00 \mathrm{~mm}$ thick; repetition time, $3000 \mathrm{~ms}$; echo time, $40 \mathrm{~ms}$ ). During each fMRI series, the right side of the bottom lip was brushed using a plastic brush at a rate of $\sim 2$ strokes/s. This stimulation paradigm was performed for a period of $10 \mathrm{fMRI}$ volumes ( $30 \mathrm{~s}$ ) after a baseline period of $10 \mathrm{fMRI}$ volumes (30 s). This was repeated an additional five times for a total of six stimulation and seven baseline periods.

Seven TNP patients classified as having trigeminal neuropathy (two males, $29 \%$ males; mean age, $48.1 \pm 1.2$ years; range, $42-51$ years) compared with 14 control subjects (four males, $29 \%$ males; mean age, $48.2 \pm 5.5$ years; range, 23-78 years) and 11 TMD patients (two males, $18 \%$ males; mean age, $42.9 \pm 3.9$ years; range, 24-66 years) compared with 13 control subjects (three males, $23 \%$ males; mean age, $42.3 \pm$ 4.8 years; range, $22-69$ years) returned up to 12 months later for a second MRI session. During TMD and TNP patients.

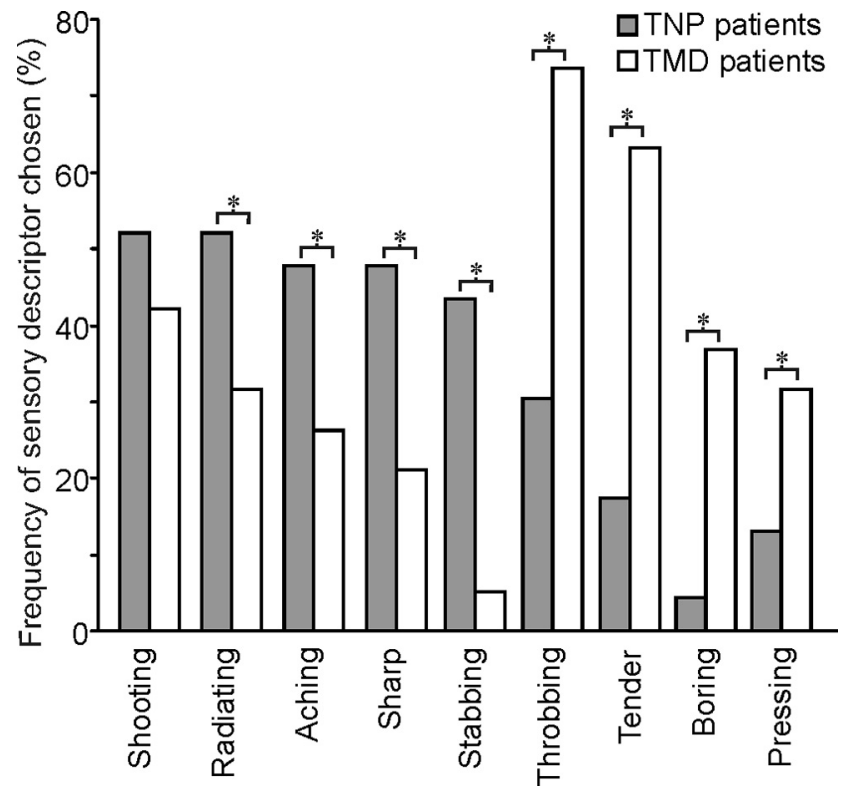

Figure 1. Frequency (percentage of subjects) of the five most common pain descriptors and the frequency of temporal characteristics selected from the McGill Pain Questionnaire by patients with TNP (gray bars) or TMD (white bars). * indicates significant differences between groups at $p<0.05$. Note that TNP was often described as shooting, radiating, and sharp, whereas TMD was most often described as throbbing, tender, and boring in nature.

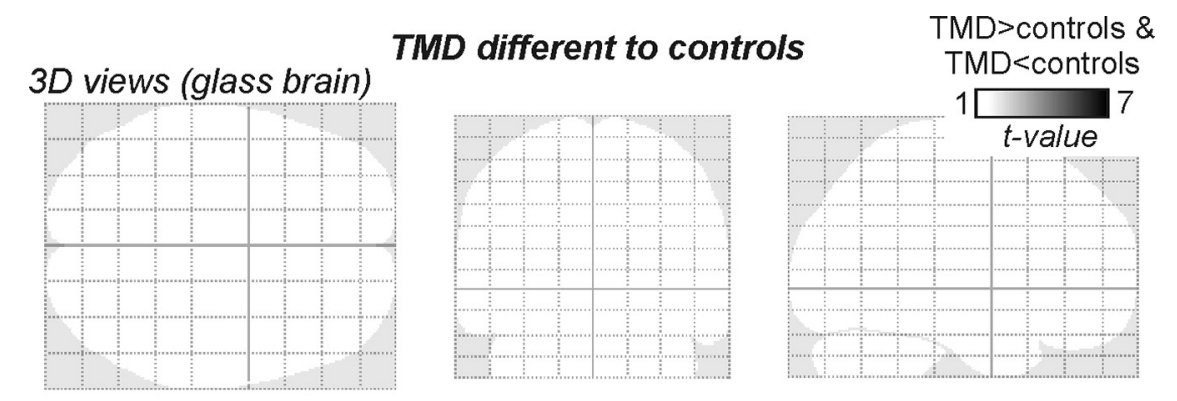

$3 D$ views (glass brain)

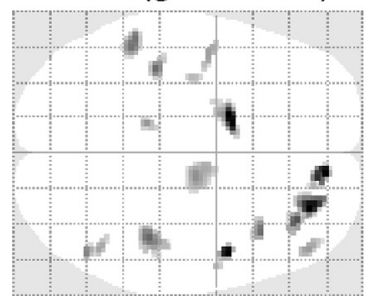

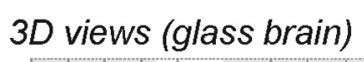

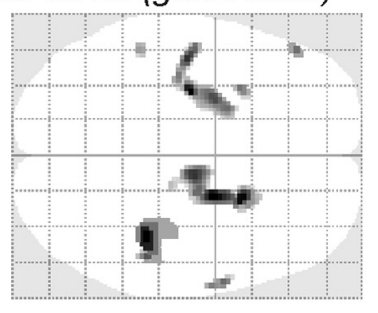

TNP different to controls

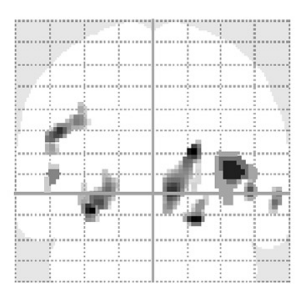

TNP different to TMD

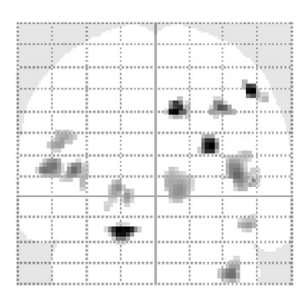

TNP $>$ controls \& TNP $<$ controls

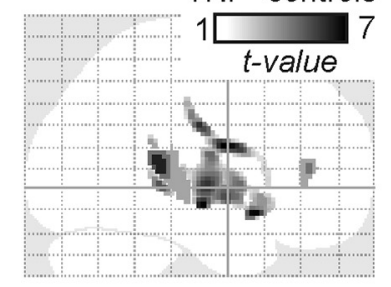

TNP $>$ TMD \& TNP $<$ TMD

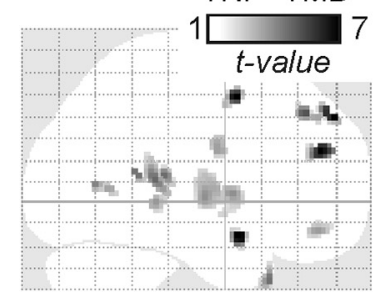

Figure 2. Glass brain views of gray matter volume changes in TMD and TNP patients compared with controls and in TMD patients compared with TNP patients. Note that TNP patients have significant regional changes in gray matter volume compared with controls, whereas TMD patients do not. Furthermore, note that there are significant gray matter volume differences between 


\section{TNP different to Controls}

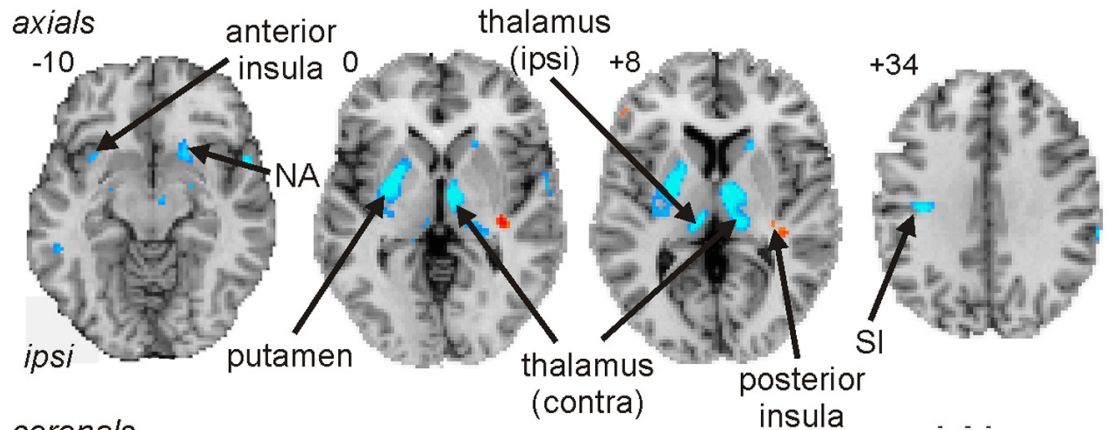

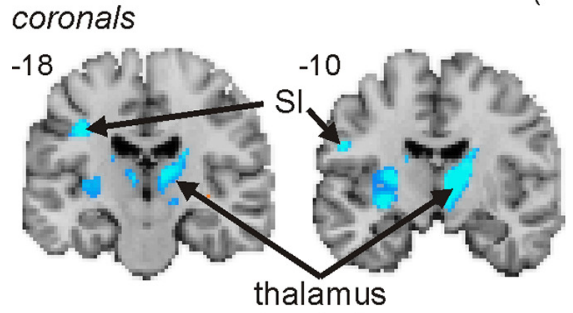

(contra)

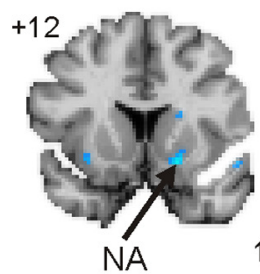

NA

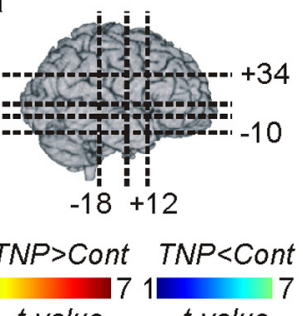

t-value t-value
TNP different to TMD

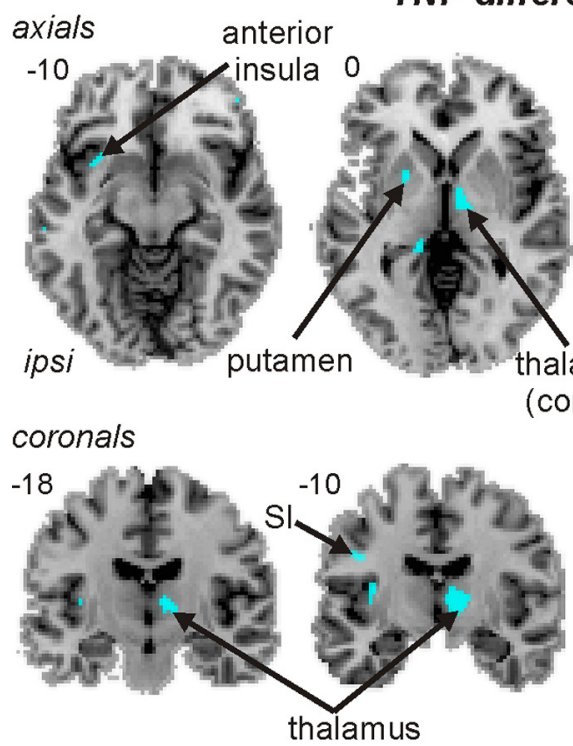

(contra)

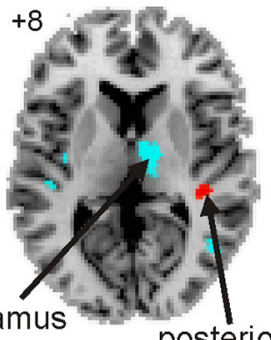

posterio

insula
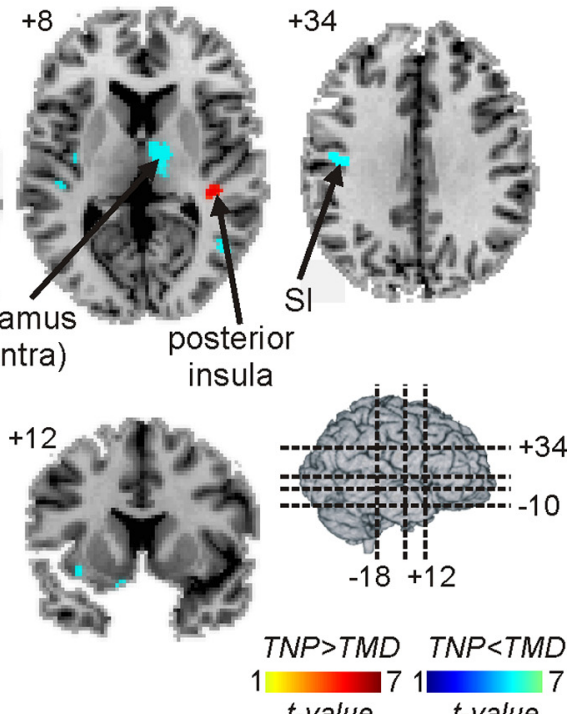

t-value 7 -value

Figure 3. Regional gray matter volume decreases (cool color scale) and increases (hot color scale) in TNP patients compared with controls and compared with TMD patients. Gray matter volume changes are overlaid onto axial and coronal slices of an individual subject's T1-weighted anatomical image set. Slice locations are indicated on the 3-D brain in the top left and by the Montreal Neurological Institute space at the top left of each slice. Note that, compared with both control and TMD subjects, TNP patients have lower gray matter volumes in the ipsilateral (ipsi) anterior insula, putamen and primary somatosensory cortex (SI), and the contralateral (contra) thalamus. Furthermore, compared with control subjects, TNP patients also had decreased gray matter volume in the ipsilateral thalamus and the contralateral nucleus accumbens (NA).

this session, MRS was performed on the left and right thalamus, again using the initial results from the VBM and fMRI investigation as a guide for voxel localization. Three series of T2-weighted anatomical scans were collected for thalamic voxel localization (62 axial, sagittal, and coronal slices; repetition time, $2.24 \mathrm{~s}$; echo time, $4.6 \mathrm{~ms}) .{ }^{1} \mathrm{H}$-spectra were then acquired with the point resolved spectroscopy sequence incorporating water suppression (echo time, $32 \mathrm{~ms}$; repetition time, $2000 \mathrm{~ms} ; 128$ repeats; voxel volume, $1 \times 1.5 \times 1 \mathrm{~cm}$ ). A total of 2048 sample points were collected at a spectral width of $2 \mathrm{kHz}$. Each subject also completed a pain diary and rated their pain at the time of scanning using the same procedures as those during the first scanning session.

\section{MRI analysis}

VBM analysis. Using SPM5 (Friston et al., 1995), the three T1-weighted images from each subject were coregistered and averaged. The averaged image was bias corrected using the SPM5 unified segmentation (Ashburner and Friston, 2005). The bias-corrected images were segmented and spatially normalized using a second pass of the unified segmentation algorithm. The result of the segmentation and spatial normalization were whole-brain "maps" of gray matter probabilities, spatially normalized into the Montreal Neurological Institute (MNI) template space, and "modulated" by the volume changes attributable to the normalization. The normalized, modulated gray matter images were smoothed (full-width at halfmaximum, $6 \mathrm{~mm}$ ). Significant differences in gray matter between TNP and control subjects as well as between TMD and controls subjects were determined using random-effects analysis with age, sex, and total brain volume as nuisance variables $(p<0.01$, corrected for multiple comparisons, false discovery rate). In 14 TNP and three TMD patients, the ongoing pain was localized either exclusively or predominantly to one side of the face (Tables 1,2). That is, on one side of the face, pain intensity was either zero or at least $75 \%$ lower than the pain intensity on the opposite side of the face. For patients with left-sided pain (five TNP, zero TMD), the T1 image sets used for VBM analysis were reflected in the $X$ plane (i.e., to the opposite side) so that each subject's brain then represented pain on the same side of the face. In this manner, we were able to assess gray matter volume changes ipsilateral and contralateral to the ongoing pain. Significant differences in gray matter volume between TNP and TMD patients were also determined using random-effects analysis with age, sex, and total brain volume as nuisance variables $(p<0.001$, uncorrected for multiple comparisons, minimum cluster size of 10 voxels). Significant gray matter volume differences were then overlaid onto an individual's T1-weighted image. Finally, within the thalamus of TNP patients, significant gray matter volumes were calculated for the trigeminal neuralgia and trigeminal neuropathy subgroups.

fMRI analysis. Using SPM5, all fMRI images were motion corrected, and global signal drifts were removed using the detrending method described by Macey et al. (2004), spatially normalized to the MNI template and spatially smoothed using a $6 \mathrm{~mm}$ full-width at halfmaximum Gaussian filter. Significant increases in fMRI signal intensity were determined using a repeated boxcar model convolved with hemodynamic delay function. Those voxels within the contralateral thalamus that displayed significant increases in signal intensity $(p<0.05$, false discovery rate corrected, minimum cluster size of 10 voxels) were determined and overlaid onto an individual's T1-weighted image.

MRS analysis. MRS data were analyzed in the time domain using the Java-based magnetic resonance user's interface (jMRUI 4.1, European Union project). First, the dominant water resonance was removed using the Hankel Lanczos Singular Valve Decomposition algorithm. The spectrum was then phased with respect to both the zero- and first-order phase. Line broadening of $5 \mathrm{~Hz}$ was used to improve the display of the 
spectra. All metabolite resonances were quantified using AMARES, a nonlinear least-square fitting algorithm operating in the time domain. Peak fitting for $N$-acetylaspartate (NAA) and creatine (Cr) was performed using Lorentzian curves to obtain the peak amplitude for these resonances, and ratios were calculated for NAA relative to creatine. Differences in metabolite ratios between TNP and TMD subjects and controls were determined used independent $t$ tests with a $p$ value of $<0.05$ taken to indicate statistical significance.

\section{Psychophysical measures}

To assess the intensity of facial pain, each TNP and TMD patient completed a pain diary for 1 week before scanning in which they indicated, with a vertical pencil stroke on a $10 \mathrm{~cm}$ horizontal line, the intensity of their pain ( $0 \mathrm{~cm}$ for "no pain" to $10 \mathrm{~cm}$ for "maximum imaginable pain") three times a day ("diary pain"). Each patient also rated their ongoing pain intensity immediately before the MRI scanning session using the same intensity scale and completed a McGill Pain Questionnaire (Melzack, 1975) to assess the nature of their pain ("scan pain"). The McGill includes a series of graded adjectives in categories related to the sensory component of pain. In addition, each patient was asked to complete two questionnaires designed to assess their affective-motivational state. The Beck Depression Inventory (BDI) (Beck et al., 1961) is a 21-item, selfreport inventory used to assess the severity of depressive symptoms; the greater the score, the greater the level of depressive symptoms (range of 0-63). The State Anxiety Index (STATE) (Spielberger et al., 1970 ) is a 20-item, self-report questionnaire used to assess transient anxiety; the greater the score, the greater the level of anxiety (range of $20-80)$.

Each TNP and TMD patient completed the McGill Pain Questionnaire and pain diary. BDI and STATE questionnaires were completed by 21 TNP patients (four males; mean age, $54.7 \pm 2.1$ years), 20 TMD patients (four males; mean age, $45.8 \pm 2.9$ years), and 32 controls ( 20 males; mean age, $48.6 \pm 3.1$ years). Differences in BDI and STATE scores between TNP and TMD subjects and controls were determined used two-tailed $t$ tests with a $p$ value of $<0.05$ taken to indicate statistical significance. In addition, significant correlations between diary pain, scan pain, pain duration, BDI and STATE values, and both the gray matter volume values in significant clusters determined in the VBM analysis and thalamic metabolite changes were determined ( $p$ value of $<0.05$ taken to indicate statistical significance).

\section{Results}

\section{Psychophysics}

Individual TMD and TNP subject characteristics are shown in Tables 1 and 2, respectively. Analgesic medication use was significantly different between TMD and TNP patients (TMD vs TNP, $\left.\chi^{2}=56.7, \mathrm{df}=3 ; p<0.001\right)$. Within the TNP patient group, $52 \%$ were taking antiepileptics, $33 \%$ nonsteroidal anti-inflammatory drugs, $13 \%$ antidepressants, $10 \%$ opioid analgesic, $5 \%$ muscle relaxants, and 5\% benzodiazepines. In contrast, within the TMD patient group, 55\% were taking nonsteroidal antiinflammatory drugs, $15 \%$ antidepressants, $15 \%$ opioid analgesic, $5 \%$ benzodiazepines, $5 \%$ serotonin agonists, and $5 \%$ botulinum toxins. In 14 TNP patients, the ongoing pain was confined to one side of the face, whereas in 17 TMD patients, the pain was bilaterally distributed. In all TNP and the vast majority of TMD patients, the pain was confined to areas innervated by the maxillary and mandibular divisions of the trigeminal nerve. The average pain intensity during the week before the scanning session was similar in the TNP and TMD groups (mean \pm SEM; TNP, $3.5 \pm$ 0.4 ; TMD, $3.7 \pm 0.5$ ).

Despite similar pain intensities, the words chosen to describe the pain were significantly different in the TNP and TMD subjects. Although both TNP and TMD patients described their pain as "shooting" (TNP vs TMD; $p=0.03$ ), a significantly greater number of TNP patients chose "radiating" $(p=0.029)$, "aching" $(p=0.011)$, "sharp" $(p=0.001)$, and "stabbing" $(p<0.001)$ to
Table 3. Montreal Neurological Institute coordinates of significant gray matter volume differences between controls and TNP patients

\begin{tabular}{lrrrrr}
\hline & \multicolumn{3}{l}{ MNI coordinates } & & \\
\cline { 2 - 5 } Brain region & $x$ & $y$ & $Z$ & Cluster size & Z-score \\
\hline Controls $>$ TNP & & & & & \\
$\quad$ Thalamus & 8 & -6 & 4 & 800 & 5.19 \\
$\quad$ Contralateral & -8 & -22 & 8 & 87 & 4.51 \\
$\quad$ Ipsilateral & -24 & -6 & 10 & 593 & 5.15 \\
$\quad$ Putamen ipsilateral & 20 & 14 & -12 & 45 & 4.18 \\
$\quad$ Nucleus accumbens contralateral & -52 & -10 & 26 & 98 & 4.77 \\
$\quad$ S1 ipsilateral & -32 & 12 & -12 & 12 & 4.14 \\
$\quad$ Anterior insula ipsilateral & & & & & \\
TNP $>$ controls & 40 & -34 & 14 & 187 & 5.38 \\
$\quad$ Posterior insula contralateral & & & & &
\end{tabular}

describe their pain. Conversely, a significantly greater number of TMD patients chose "throbbing" $(p<0.001)$, "tender" $(p<$ $0.001)$, "boring" $(p<0.001)$, and "pressing" $(p=0.005)$ to describe their ongoing pain (Fig. 1).

Despite differences in the sensory qualities of ongoing pain, the TNP and TMD patients reported similar affective-motivational states, i.e., they reported similar BDI (depression) and STATE (anxiety) scores, although both pain groups had significantly greater values compared with controls (BDI: mean \pm SEM; TNP, $10.9 \pm 1.7$; TMD, $12.4 \pm 1.7$; controls, $3.8 \pm 0.6$; TNP $>$ controls, $p<0.001$; TMD $>$ controls, $p<0.0001$; STATE: TNP, $33.7 \pm 1.81$; TMD, $36.4 \pm 2.5$; controls, $28.0 \pm 1.7$; TNP $>$ controls, $p<0.05$; TMD $>$ controls, $p=0.05)$. Although TNP subjects were significantly older compared with TMD subjects $(p=0.017)$, age was not identified as a significant covariate in the two affective-motivational measures.

\section{Gray matter volume changes (VBM)}

In TMD patients, VBM analysis revealed no significant change in regional gray matter volume compared with control subjects. In contrast, TNP subjects displayed significant regional gray matter volume changes in a number of brain regions (Fig. 2). Compared with control subjects, significant reductions in gray matter volume occurred in the anterior insula, putamen, thalamus, and primary somatosensory cortex on the side ipsilateral to the ongoing pain (Fig. 3, Table 3). On the side contralateral to ongoing pain, gray matter was reduced in the thalamus and nucleus accumbens, and gray matter volume was increased in the region of the posterior insula (Fig. 3, Table 3). Furthermore, a direct comparison between TNP and TMD groups revealed regions of gray matter volume change that were strikingly similar to those observed in the comparison between TNP patients and controls. That is, compared with TMD patients, TNP patients had reduced gray matter volume in the ipsilateral anterior insula, putamen, and primary somatosensory cortex and the contralateral thalamus, and gray matter volume increases in the contralateral posterior insula and dorsolateral prefrontal cortex (Figs. 2, 3, Table 4). Innocuous brushing of the lip evoked activation within a discrete region of the contralateral thalamus (Fig. 4, left) that overlapped the gray matter loss in the TNP patients (Fig. 4, middle and right). Furthermore, gray matter volume in this region of overlap (the ventroposterior thalamic nucleus) was negatively correlated to diary pain in TNP but not TMD patients (TNP, $r=$ $-0.59, p<0.05$; TMD, $r=-0.24, p>0.05)$. Thus, in TNP patients, as pain intensity increased, thalamic volume decreased. Thalamic gray matter volume was not correlated to either scan pain (TNP, $r=-0.23, p>0.05$; TMD, $r=-0.09, p>0.05$ ) or 
Table 4. Montreal Neurological Institute coordinates of significant gray matter volume differences between TNP and TMD patients

\begin{tabular}{|c|c|c|c|c|c|}
\hline \multirow[b]{2}{*}{ Brain region } & \multicolumn{3}{|c|}{ MNI coordinates } & \multirow[b]{2}{*}{ Cluster size } & \multirow[b]{2}{*}{ Z-score } \\
\hline & $x$ & $y$ & $z$ & & \\
\hline \multicolumn{6}{|l|}{ TMD $>$ TNP } \\
\hline Thalamus contralateral & 12 & -10 & 2 & 173 & 3.16 \\
\hline Putamen ipsilateral & -18 & 4 & 4 & 49 & 3.16 \\
\hline S1 ipsilateral & -46 & -4 & 26 & 22 & 3.06 \\
\hline Anterior insula ipsilateral & -32 & 12 & -10 & 18 & 3.02 \\
\hline \multicolumn{6}{|l|}{ TMD $<$ TNP } \\
\hline Posterior insula contralateral & 40 & -32 & 10 & 101 & 4.2 \\
\hline Dorsolateral prefrontal cortex contralateral & 28 & 46 & 24 & 83 & 5.04 \\
\hline
\end{tabular}

S1, Primary somatosensory cortex.
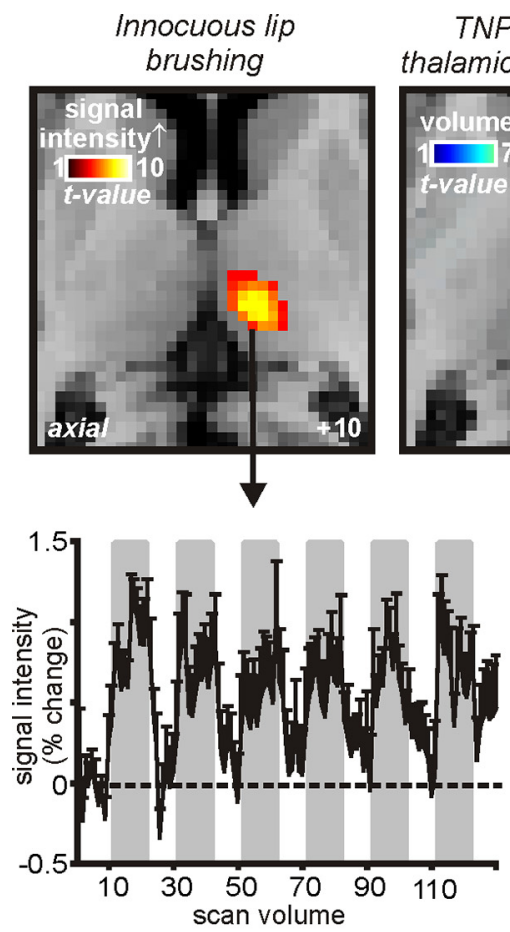

TNP contralateral thalamic grey matter loss

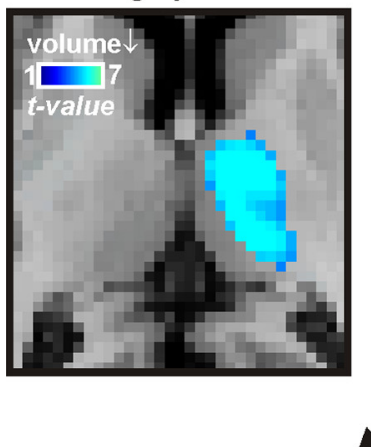

Lip brush, grey matter loss overlap

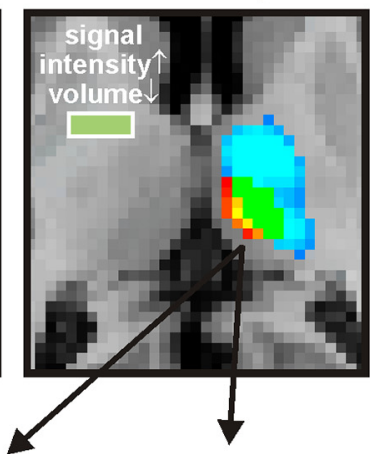

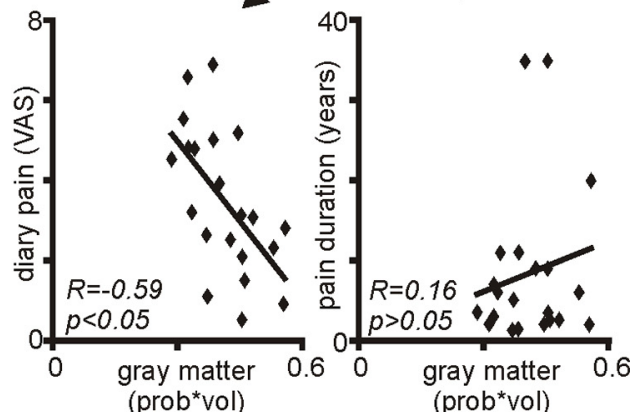

Figure 4. Gray matter volume decreases in the contralateral thalamus of TNP patients and contralateral (contra) thalamic activity increases during innocuous brushing of the lower lip overlaid onto axial slices of an individual subject's T1-weighted anatomical image set. Light blue indicates gray matter volume decrease, red indicates activity increases during lip brushing, and yellow indicates where both gray matter volume decreased and activity (signal intensity) increased. Slice location in Montreal Neurological Institute space is indicated on the bottom right of the left slice. Bottom left shows mean \pm SEM percentage change in signal intensity plotted against time for the contralateral thalamus. The gray bars indicate the periods during which the lower lip was lightly brushed with a plastic brush. Bottom middle and right show plots of gray matter volume decrease (prob * vol) in the area of overlap (i.e., yellow shading, the ventroposterior thalamus) against ongoing diary pain, as indicated on a continuous visual-analog scale (VAS) (bottom middle) and against pain duration (bottom right). Note the significant negative correlation between gray matter volume and pain, i.e., the greater the pain, the greater the reduction in gray matter volume. matter volume in trigeminal neuralgia patients, whereas trigem$0.27 \pm 0.01(n=47)$; trigeminal neuralgia, $0.24 \pm 0.02(n=8)$

\section{Thalamic biochemical changes (MRS)} was a significant reduction in gray matter in the seven trigeminal uropathy patients. A typical ${ }^{1} \mathrm{H}$-spectra in an individual subis also shown in Figure 6 (top right). Analysis of ${ }^{1} \mathrm{H}$-spectra revealed that the NAA/Cr ratio was significantly reduced in the thalamus contralateral to the ongoing pain (affected side) compared with controls in trigeminal neuropathy patients (Fig. 6, bottom right) (NAA/ Cr: trigeminal neuropathy, 1.64; controls, 2.06; trigeminal neuropathy vs controls, $t=-4.38, \mathrm{df}=11 ; p=0.001)$. Furthermore, NAA/Cr in the affected thalamus of unilateral trigeminal neuropathy patients was also significantly reduced compared with the unaffected side (NAA/Cr: affected, 1.79; unaffected, 2.00; affected vs unaffected, $t=-4.49$, df $=3 ; p=0.02$ ) and compared with the thalami of TMD patients (NAA/Cr: trigeminal neuropathy, 1.64, TMD, 2.04; trigeminal neuropathy vs TMD, $t=3.49, \mathrm{df}=14 ; p=0.004$ ). In direct contrast to trigeminal neuropathy patients, there was no significant change in $\mathrm{NAA} / \mathrm{Cr}$ in the thalami of TMD patients compared with controls (NAA/Cr: TMD, 2.04; controls, 2.08; TMD vs controls, $t=-0.39$, $\mathrm{df}=17 ; p=0.71)$.

Similar to gray matter volume, thalamic NAA/Cr on the affected side was negatively correlated to diary pain scores in trigeminal neuropathy but not TMD patients (trigeminal neuropathy, $r=-0.51, p<0.05$;MD, $r=-0.34$, $p>0.05)$. That is, in trigeminal neuropathy patients, as pain intensity increased, thalamic NAA/Cr decreased. Furthermore, in trigeminal neuropathy but not TMD patients, NAA/Cr was also correlated to pain duration (pain duration: trigeminal neuropathy, $r=-0.67, p<0.05$; TMD, $r=-0.20, p>0.05)$. In neither trigeminal neuropathy nor TMD patients was NAA/Cr significantly correlated to pain duration (TNP, $r=0.16, p>0.05$; TMD, $r=-0.09, p>$ 0.05 ) even with outliers (i.e., patients with $>30$ years pain duration) removed. BDI scores were not significantly correlated to gray matter volume in any of the clusters that displayed a significant difference in TNP patients compared with controls. Furthermore, in all clusters except for the thalamus, no significant relationship occurred between gray matter volume and STATE scores $(r=-0.57, p<0.05)$.

Dividing the TNP patients into two subgroups (trigeminal neuralgia and trigeminal neuropathy) revealed that the 13 trigeminal neuropathy patients were responsible for the significant thalamic gray matter volume decrease (Fig. 5). That is, there was no significant difference compared with controls in thalamic gray
BDI or STATE values (BDI: trigeminal neuropathy, $r=0.07, p>$ 0.05 ; TMD $, r=0.05, p>0.05$; STATE: trigeminal neuropathy, $r=0.19, p>0.05$; TMD $, r=0.14, p>0.05)$.

\section{Discussion}

The results of this investigation reveal that, in contrast to nonneuropathic orofacial pain, neuropathic orofacial pain was associated with significant changes in gray matter volume. Compared with both controls and non-neuropathic pain patients, gray matter volume of neuropathic pain patients was reduced in the primary somatosensory cortex, anterior insular, putamen, nucleus accumbens, and the thalamus, whereas gray matter volume was increased in the posterior insula. Furthermore, within the thalamus, the volume de- 


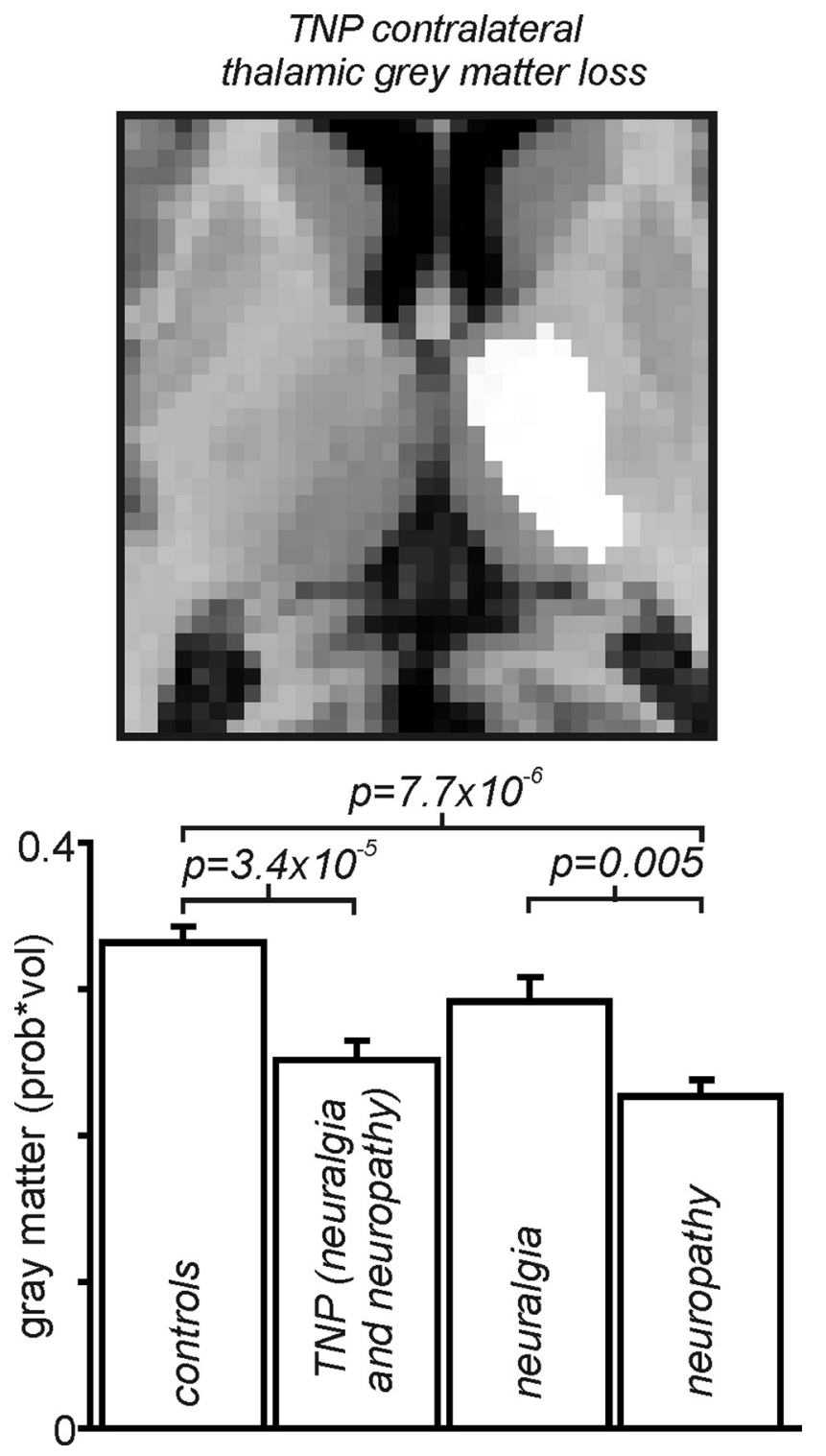

Figure 5. Top, Thalamic region in which gray matter volume decreased (measured using VBM) in TNP patients compared with controls, overlaid onto an individual subject's T1weighted anatomical axial image. Bottom, Mean \pm SEM gray matter volumes in the thalamic region indicated on the left, in controls, all TNP patients (trigeminal neuralgia and neuropathy combined), trigeminal neuralgia, and trigeminal neuropathy patients, respectively, from left to right. It is clear that thalamic gray matter volume loss in TNP patients is because of the volume loss in the trigeminal neuropathy patients but not the trigeminal neuralgia patients.

crease was specifically associated with one subgroup of neuropathic pain patients, i.e., thalamic volume decreased in patients with trigeminal neuropathy but not trigeminal neuralgia. Additionally, in trigeminal neuropathy patients, in the region of thalamic volume loss, magnetic resonance spectroscopy revealed a significant reduction in the $\mathrm{N}$-acetylaspartate/creatine ratio, a biochemical marker of neural viability. In direct contrast, chronic non-neuropathic orofacial pain was not associated with any significant change in brain gray matter volume or in thalamic neural viability.

\section{Brain anatomical changes and neuropathic pain}

The idea that higher centers play a critical role in the generation and/or maintenance of chronic pain was suggested almost half a century ago. In 1978, Melzack and Loeser wrote the following: "There is no denying the role of neuromas, nerve injury ... as initiators of abnormal central processes, but once the abnormal central pattern generating processes are underway, the peripheral contributions may assume less importance." They proposed that some neuropathic pain conditions result from neural processes well above the level of the primary synapse and may result exclusively from activity in a central pattern generator.

Indeed, there is growing recent evidence showing that chronic neuropathic pain is associated with changes in brain structure. Several volumetric studies have shown that neuropathic pain is associated with changes in the thalamus, nucleus accumbens, and insular, posterior parietal, cingulate, and dorsolateral prefrontal cortices (Apkarian et al., 2004; Kuchinad et al., 2007; Buckalew et al., 2008; DaSilva et al., 2008; Kim et al., 2008). Furthermore, using diffusion tensor imaging, we have shown previously that neuropathic pain after complete spinal cord injury is associated with structural alterations in the VP thalamus, nucleus accumbens, ventral pons, and posterior parietal, dorsolateral prefrontal, and medial orbitofrontal cortices (Gustin et al., 2010). In this previous investigation, we also provided evidence to suggest that the changes in the VP thalamus appear to result from the injury itself, whereas structural changes in higher cortical regions may preexist the injury and predispose an individual to the development of chronic pain.

\section{Neuropathic pain and the thalamus}

The most striking finding of this investigation is that thalamic volume and neural viability is reduced only in trigeminal neuropathy and not trigeminal neuralgia or TMD patients. TMD are characterized by throbbing, tender, continuous pain and result from or are initiated by activation of nociceptors in the temporomandibular joint and/or muscles of mastication (Sarlani and Greenspan, 2005; Ro, 2008; Sessle et al., 2008; Manfredini and Nardini, 2010). In contrast, trigeminal neuralgia is characterized by intermittent periods of sharp, electricity-like, shooting pain that results primarily from compression of the trigeminal root entry zone by an arterial vessel (Meaney et al., 1995; Hamlyn, 1997). Indeed, surgical interventions in which the offending artery is physically separated from the trigeminal nerve are successful at relieving this type of pain (Meaney et al., 1995; Leandri et al., 1998). Given these observations, it is thought that TMD and trigeminal neuralgia result from peripheral events, i.e., nociceptor or nerve root.

In contrast, trigeminal neuropathy patients describe a dull or sharp continuous pain that often lasts for hours. Remarkably, our data show that only trigeminal neuropathy patients display significant reductions in thalamic volume and neural viability, including the region of the ventroposterior nucleus. Because NAA is localized almost exclusively in mature neurons and neuronal processes and is considered a putative marker of the number and viability of neurons (Urenjak et al., 1993), the reduction in thalamic NAA/Cr in trigeminal neuropathy patients likely reflects a reduction in local neurons. Indeed, in the macaque, peripheral nerve lesions result in GABA receptor downregulation (Rausell et al., 1992), and somatosensory pathway lesions reduce GABAimmunoreactive synapses by up to $50 \%$ within the VP thalamus (Ralston, 2005). Although no direct observations of GABAergic loss in human neuropathic syndromes have been made, indirect evidence for an imbalance in excitatory/inhibitory neurotransmission comes from the relative success of the GABA-derivative drugs gabapentin and pregabalin in the control of neuropathic pain. We speculate that a large reduction in local GABAergic neurons is at least partially responsible for the significant reduction in thalamic gray matter volume in TNP patients.

In addition to neural viability, other cellular changes may also occur in the thalami of trigeminal neuropathy patients. In a ro- 


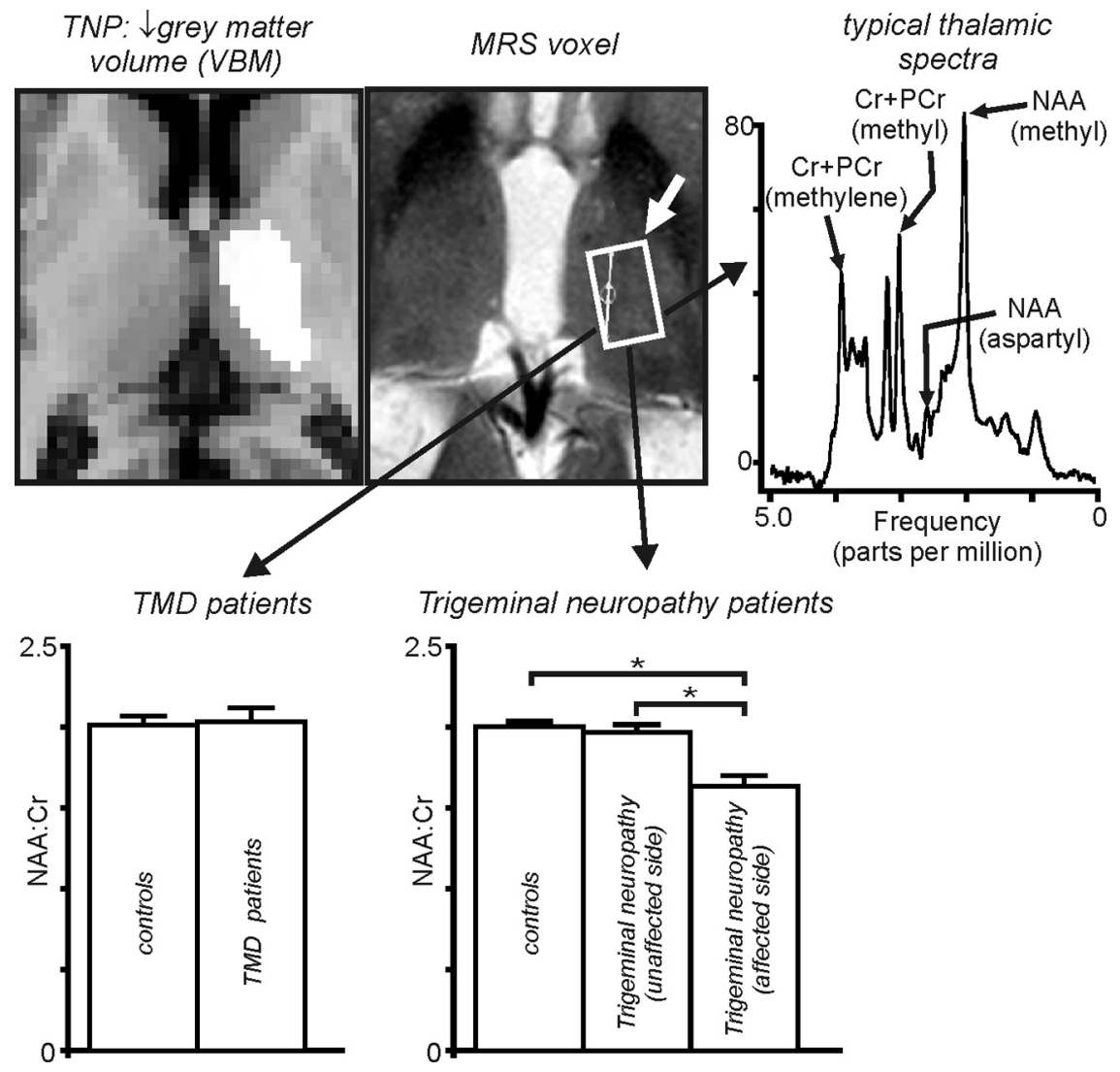

Figure 6. Top, Thalamic region in which gray matter volume decreased in TNP patients and region from which $\mathrm{H}^{1}$-spectra were collected. To the right is a typical $\mathrm{H}^{1}$-spectra. $\mathrm{PCr}$, Phosphocreatine. Bottom, Left, NAA/Cr within the ventroposterior thalamus in controls, TMD, and trigeminal neuropathy patients on the side ipsilateral (unaffected side) and contralateral (affected side) to ongoing pain. Note that, although there is no significant change in NAA/Cr in TMD patients, NAA/Cr is significantly reduced in the thalamus on the side contralateral to the ongoing pain in trigeminal neuropathy patients. ${ }^{*} p<0.05$.

dent model of neuropathic pain, remote, transynaptic microglial activation occurs in the VP thalamus (Detloff et al., 2008). Furthermore, in a rodent model of VP thalamic central post-stroke pain, it was suggested that alterations in the physiology of surviving neurons surrounding a thalamic lesion, coupled with activated microglia contribute to the generation of pain (Wasserman and Koeberle, 2009). In humans, Banati et al. (2001) reported significantly increased binding of $\left[{ }^{11} \mathrm{C}\right](R)$-PK11195, a marker of microglial activation, specifically within the region of the VP thalamus of neuropathic pain patients (2-23 years duration). Furthermore, Banati (2002) suggests that these thalamic microglial changes may be linked to sensory cortex reorganization reported to occur in neuropathic pain patients.

Although a role for the thalamus in neuropathic pain remains under debate, there is good evidence for a thalamic role in CPSP. CPSP often results from VP thalamic lesions (Kim, 1992; Kim et al., 2007) and is associated with increased VP thalamic bursting (Lenz et al., 1989; Wang and Thompson, 2008). For the main part, the proposed models underlying CPSP involve reduced activity or inhibition of the medial and/or lateral thalamus by the ascending spinothalamic tracts (Klit et al., 2009). Increased drive on the medial thalamus by the lateral thalamus may result in increased thalamocortical activity and the perception of pain. Because we found both medial and lateral thalamic volume reductions in trigeminal neuropathy patients, it is possible that a similar mechanism also occurs in this and possibly other neuropathic pain conditions. Indeed, Sarnthein and Jeanmonod (2008) recently reported high median thalamocortical coherence within the centrolateral thalamic nucleus of patients with trigeminal neuropathic pain. These and our data suggest that neuropathic pain results from changes in the coupling of thalamocortical loops, possibly as a result of thalamic neural loss.

\section{The lack of anatomical changes in non-neuropathic pain}

A few investigations have also focused on gray matter changes in pain of nonneuropathic origin. For example, fibromyalgia, a condition similar to TMD, is associated with changes in amygdala, cingulate, prefrontal, and insular cortex volumes (Kuchinad et al., 2007); Burgmer et al. (2009) and Younger et al. (2010) recently reported increased thalamus, insula, and putamen volumes in TMD patients. Even at a lowered statistical threshold of uncorrected $p<0.01$, significant gray matter volume increases in these regions failed to emerge. It is unclear why our data and the results from this previous investigation differ, although it may result from the fact that our TMD subjects had greater pain durations (11.5 years) than those in this previous study (4.4 years). Alternatively, it has been reported that repeated noxious stimulation in healthy controls results in increased gray matter volume in the primary somatosensory and cingulate cortices (Teutsch et al., 2008). Because TMD results primarily from constant nociceptor activation, it is possible that the gray matter increases reported by Younger et al. (2010) reflect adaptive changes attributable to constant activity that subside over time. Furthermore, it has been reported recently that volume decreases in regions that process emotional state changes, e.g., the insula cortex, are related to the fibromyalgia patient's affective state and not the presence of pain per se (Hsu et al., 2009). Given this, it is likely that the lack of gray matter changes seen in our TMD patients reflects the fact that they had only mild affective state changes compared with healthy controls.

Although approximately one-third of TMD and TNP patients were not taking any medication, approximately half of the TNP patients were taking antiepileptics, whereas approximately half of the TMD patients were taking nonsteroidal anti-inflammatory drugs. It is possible that this difference in medication use may have influenced our results. Furthermore, because our data revealed that pain subclassification has a significant effect on changes in regional brain volume, it is possible that additional subclassification of TMD and TNP patients may reveal further insights into the underlying mechanisms of various chronic pain states.

\section{Conclusions}

The data presented here show that neuropathic, and not nonneuropathic, orofacial pain is associated with significant changes in brain structure and biochemistry, including decreased thalamic volume and neural viability. Furthermore, division of TNP patients into subgroups revealed that the reduction in thalamic volume occurred in trigeminal neuropathy and not trigeminal neuralgia patients. 
These data strongly suggest that the pathogenesis underlying neuropathic and non-neuropathic pain conditions are fundamentally different and that chronic pain conditions that result from peripheral injuries may be generated and/or maintained by structural changes in regions such as the thalamus.

\section{References}

Apkarian AV, Sosa Y, Sonty S, Levy RM, Harden RN, Parrish TB, Gitelman DR (2004) Chronic back pain is associated with decreased prefrontal and thalamic gray matter density. J Neurosci 24:10410-10415.

Ashburner J, Friston KJ (2005) Unified segmentation. Neuroimage 26:839851.

Banati RB (2002) Brain plasticity and microglia: is transsynaptic glial activation in the thalamus after limb denervation linked to cortical plasticity and central sensitisation? J Physiol Paris 96:289-299.

Banati RB, Cagnin A, Brooks DJ, Gunn RN, Myers R, Jones T, Birch R, Anand P (2001) Long-term trans-synaptic glial responses in the human thalamus after peripheral nerve injury. Neuroreport 12:3439-3442.

Beck AT, Ward CH, Mendelson M, Mock J, Erbaugh J (1961) An inventory for measuring depression. Arch Gen Psychiatry 4:561-571.

Buckalew N, Haut MW, Morrow L, Weiner D (2008) Chronic pain is associated with brain volume loss in older adults: preliminary evidence. Pain Med 9:240-248.

Burgmer M, Gaubitz M, Konrad C, Wrenger M, Hilgart S, Heuft G, Pfleiderer B (2009) Decreased gray matter volumes in the cingulo-frontal cortex and the amygdala in patients with fibromyalgia. Psychosom Med 71:566-573.

DaSilva AF, Becerra L, Pendse G, Chizh B, Tully S, Borsook D (2008) Colocalized structural and functional changes in the cortex of patients with trigeminal neuropathic pain. PLoS One 3:e3396.

Davis KD, Kiss ZH, Tasker RR, Dostrovsky JO (1996) Thalamic stimulationevoked sensations in chronic pain patients and in nonpain (movement disorder) patients. J Neurophysiol 75:1026-1037.

Detloff MR, Fisher LC, McGaughy V, Longbrake EE, Popovich PG, Basso DM (2008) Remote activation of microglia and pro-inflammatory cytokines predict the onset and severity of below-level neuropathic pain after spinal cord injury in rats. Exp Neurol 212:337-347.

Dworkin SF, LeResche L (1992) Research diagnostic criteria for temporomandibular disorders: review, criteria, examinations and specifications, critique. J Craniomandib Disord 6:301-355.

Friston KJ, Holmes AP, Worsley KP, Proline JB, Frith CD, Frackowiak RSJ (1995) Statistical parametric maps in functional imaging: a general imaging approach. Hum Brain Mapp 2:189-210.

Gustin SM, Wrigley PJ, Siddall PJ, Henderson LA (2010) Brain anatomy changes associated with persistent neuropathic pain following spinal cord injury. Cereb Cortex 20:1409-1419.

Hamlyn PJ (1997) Neurovascular relationships in the posterior cranial fossa, with special reference to trigeminal neuralgia. 2. Neurovascular compression of the trigeminal nerve in cadaveric controls and patients with trigeminal neuralgia: quantification and influence of method. Clin Anat 10:380-388.

Hsu MC, Harris RE, Sundgren PC, Welsh RC, Fernandes CR, Clauw DJ, Williams DA (2009) No consistent difference in gray matter volume between individuals with fibromyalgia and age-matched healthy subjects when controlling for affective disorder. Pain 143:262-267.

Kim JH, Greenspan JD, Coghill RC, Ohara S, Lenz FA (2007) Lesions limited to the human thalamic principal somatosensory nucleus (ventral caudal) are associated with loss of cold sensations and central pain. J Neurosci 27:4995-5004.

Kim JH, Suh SI, Seol HY, Oh K, Seo WK, Yu SW, Park KW, Koh SB (2008) Regional grey matter changes in patients with migraine: a voxel-based morphometry study. Cephalalgia 28:598-604.

Kim JS (1992) Pure sensory stroke. Clinical-radiological correlates of 21 cases. Stroke 23:983-987.

Klit H, Finnerup NB, Jensen TS (2009) Central post-stroke pain: clinical characteristics, pathophysiology, and management. Lancet Neurol 8:857-868.

Kuchinad A, Schweinhardt P, Seminowicz DA, Wood PB, Chizh BA, Bushnell MC (2007) Accelerated brain gray matter loss in fibromyalgia patients: premature aging of the brain? J Neurosci 27:4004-4007.

Leandri M, Eldridge P, Miles J (1998) Recovery of nerve conduction following microvascular decompression for trigeminal neuralgia. Neurology 51:1641-1646.
Lenz FA, Kwan HC, Dostrovsky JO, Tasker RR (1989) Characteristics of the bursting pattern of action potentials that occurs in the thalamus of patients with central pain. Brain Res 496:357-360.

Lenz FA, Seike M, Richardson RT, Lin YC, Baker FH, Khoja I, Jaeger CJ, Gracely RH (1993) Thermal and pain sensations evoked by microstimulation in the area of human ventrocaudal nucleus. J Neurophysiol 70:200-212.

Macey PM, Macey KE, Kumar R, Harper RM (2004) A method for removal of global effects from fMRI time series. Neuroimage 22:360-366.

Manfredini D, Nardini LG (2010) TMD classification and epidemiology. In: Current concepts on temporomandibular disorders (Manfredini D, ed), pp 25-39. London: Quintessence Publishing Company.

Meaney JF, Eldridge PR, Dunn LT, Nixon TE, Whitehouse GH, Miles JB (1995) Demonstration of neurovascular compression in trigeminal neuralgia with magnetic resonance imaging: comparison with surgical findings in 52 consecutive operative cases. J Neurosurg 83:799-805.

Melzack R (1975) The McGill Pain Questionnaire: major properties and scoring methods. Pain Med 1:277-299.

Nurmikko TJ, Eldridge PR (2001) Trigeminal neuralgia-pathophysiology, diagnosis and current treatment. Br J Anaesth 87:117-132.

Pattany PM, Yezierski RP, Widerström-Noga EG, Bowen BC, MartinezArizala A, Garcia BR, Quencer RM (2002) Proton magnetic resonance spectroscopy of the thalamus in patients with chronic neuropathic pain after spinal cord injury. AJNR Am J Neuroradiol 23:901-905.

Ralston HJ 3rd (2005) Pain and the primate thalamus. Prog Brain Res 149:1-10.

Rausell E, Cusick CG, Taub E, Jones EG (1992) Chronic deafferentation in monkeys differentially affects nociceptive and nonnociceptive pathways distinguished by specific calcium-binding proteins and down-regulates gamma-aminobutyric acid type A receptors at thalamic levels. Proc Natl Acad Sci U S A 89:2571-2575.

Ro JY (2008) Functional role of peripheral glutamate receptors in craniofacial muscle pain and hyperalgesia. In: Fundamentals of musculoskeletal pain (Graven-Nielsen T, Arendt-Nielsen L, Mense S, eds), pp 33-45. Seattle: IASP.

Sarlani E, Greenspan JD (2005) Why look in the brain for answers to temporomandibular disorder pain? Cells Tissues Organs 180:69-75.

Sarlani E, Balciunas BA, Grace EG (2005) Orofacial pain. I. Assessment and management of musculoskeletal and neuropathic causes. AACN Clin Issues 16:333-346.

Sarnthein J, Jeanmonod D (2008) High thalamocortical theta coherence in patients with neurogenic pain. Neuroimage 39:1910-1917.

Schmidt-Wilcke T, Luerding R, Weigand T, Jurgens T, Schuierer G, Leinisch E, Bogdahn U (2007) Striatal grey matter increase in patients suffering from fibromyalgia: a voxel-based morphometry study. Pain 132 [Suppl 1]:S109-S116.

Schweinhardt P, Kuchinad A, Pukall CF, Bushnell MC (2008) Increased gray matter density in young women with chronic vulvar pain. Pain 140:411-419.

Sessle BJ, Iwata K, Dubner R (2008) Central nociceptive pathways. In: Orofacial pain: from basic science to clinical management, Ed 2 (Sessle BJ, Lavigne G, Lund JP, eds), pp 35-43. Chicago: Quintessence Publishing Company.

Spielberger CD, Gorsuch RL, Lushene R (1970) Manual for the state-trait anxiety inventory. Palo Alto: Consulting Psychologists' Press.

Teutsch S, Herken W, Bingel U, Schoell E, May A (2008) Changes in brain gray matter due to repetitive painful stimulation. Neuroimage 42:845-849.

Treede RD, Jensen TS, Campbell JN, Cruccu G, Dostrovsky JO, Griffin JW, Hansson P, Hughes R, Nurmikko T, Serra J (2008) Neuropathic pain: redefinition and a grading system for clinical and research purposes. Neurology 70:1630-1635.

Urenjak J, Williams SR, Gadian DG, Noble M (1993) Proton nuclear magnetic resonance spectroscopy unambiguously identifies different neural cell types. J Neurosci 13:981-989.

Wang G, Thompson SM (2008) Maladaptive homeostatic plasticity in a rodent model of central pain syndrome: thalamic hyperexcitability after spinothalamic tract lesions. J Neurosci 28:11959-11969.

Wasserman JK, Koeberle PD (2009) Development and characterization of a hemorrhagic rat model of central post-stroke pain. Neuroscience 161:173-183.

Younger JW, Shen YF, Goddard G, Mackey SC (2010) Chronic myofascial temporomandibular pain is associated with neural abnormalities in the trigeminal and limbic systems. Pain 149:222-228. 